\title{
SR-Can: Safety assessment of a repository for spent fuel - methods and effects on the biosphere
}

\author{
U. Kautsky ${ }^{1}$, L. Kumblad ${ }^{2}$, T. Lindborg ${ }^{1}$ and J . J ones ${ }^{1}$ \\ ${ }^{1}$ SKB (Swedish Nuclear Fuel and Waste Management Co.) PO Box 5864, \\ 10240 Stockholm, Sweden \\ ${ }^{2}$ Department of Systems Ecology, Stockholm University, 10691 Stockholm, Sweden
}

\begin{abstract}
During the next few years the Swedish Nuclear Fuel and Waste Management Co. (SKB) performs site investigations at two sites in Sweden for a future repository of spent nuclear fuel. Parallel an encapsulation plant is planned to encapsulate the spent fuel in copper canister according to the KBS-3 method. The purpose of the SR-Can safety assessment is to show the performance of the canister isolation at different sites for a repository at 500 meters depth in crystalline rock. Moreover SR-Can provides an example how the site specific safety assessment of a deep repository will be made in year 2006-2008.

To able to calculate dose and risk for humans and the environment new assessment method were developed for the biosphere. These methods were based on a systems ecological modelling approach and used knowledge from landscape ecology to provide an integrated approach with hydrology and geology considering the discharges in a watershed and calculating consequences in terrestrial and aquatic ecosystems. A range of methods and tools were developed with the aid of GIS and the softwares Matlab/Simulink which facilitated the modelling and increased the understanding of the important processes in the landscape today and the next few thousands of years.

In this paper an overview of the program and the novel methods are presented as well as some examples from performance calculations from a watershed in the Forsmark area considering effects on humans and ecosystems.
\end{abstract}

\section{INTRODUCTION}

During the next few years the Swedish Nuclear Fuel and Waste Management Co. (SKB) performs site investigations at two sites in Sweden for the potential localisation of a future repository of spent nuclear fuel. For this process several safety assessments need to be performed. Recently an interim safety assessment of an encapsulation plant was completed calleed SR-Can Interim report [1]. The final safety assessment of the encapsulation plants will support SKB's application to build an encapsulation plant for spent nuclear fuel and is to be completed in 2006. The purpose of the interim report is to demonstrate the methodology for the safety assessment and to provide a possibility to review the chosen methodologies before the area is used in the final license application. The assessment relates to the KBS 3 disposal concept in which copper canisters with a cast iron insert containing spent nuclear fuel are surrounded with bentonite clay and deposited at approximately $500 \mathrm{~m}$ depth in saturated, granite rock [1]. Preliminary data from the Forsmark site, presently being investigated by SKB as one of the candidate for the KBS 3 repository, are used to some extent as examples. Other important purposes of the interim SR-Can assessment were also to demonstrate the proper handling of requirements on the safety assessment in applicable regulations and to provide examples on how site specific data are used in the safety assessment. 
During the last years a strategy has been developed for how to collect relevant data from the sites, e.g. for the biosphere [2]. Field data from the site investigations [e.g. 1] are sampled and analysed by a site analysis group that produces a site descriptive model of the geosphere and the biosphere at each site [e.g. 3]. Thus, the site descriptive models are synthesis of observations of the current state of the sites and of the understanding of past and ongoing processes driven by e.g. land rise and long-term climate changes. The site descriptive models of the biospheres not only contain descriptions of the ecosystems at the sites, but are also accompanied by a thorough description of the inter-disciplinary analysis and interpretation the work underpinning it.

The results of the safety assessment will provide feedback to further site investigations and the design of the repository. Regarding the site descriptive models, an overall assessment of their confidence will be made within the safety assessment, where for instance the insights from the site analysis group will be considered.

The biosphere is an essential part of the system that has to be well understood and analysed in a safety assessment of a nuclear waste repository, since this is where the consequences of a potential release will occur. For the time scales of relevance for the safety assessment (up to million years), the biosphere will undergo considerable development, involving e.g. periods of permafrost and glacial conditions or extended warm periods. Due to expected shore-line displacements over a glacial period, coastal sites are likely to be submerged for extended periods of time, leading to both stagnant groundwater and potentially a considerable dilution of any releases from the geosphere (though also with the possibility of accumulation in bottom sediments). Glacial conditions, meaning that the site is covered by ice, will for obvious reasons lead to very low, if any doses. The highest doses are expected for the parts of temperate periods during which the site is not submerged, an assumption that also needs to be further supported by explicit calculations.

Releases from the repository are expected to be negligible for thousands of years into the future when today's biosphere has undergone development [1]. Nevertheless, it is essential to obtain a thorough understanding of the current biosphere since this is the best available basis for a description of future biospheres during temperate conditions. Also, an important factor affecting the biosphere structure is the position of the shore-line which is fairly predictable, partly since it is strongly related to the local topography. Furthermore, much of the knowledge required to describe the functioning of the biosphere is generic in nature, meaning that results regarding the current biosphere are applicable also for altered future biosphere conditions. Studying and analysing the biosphere is therefore an essential part of the ongoing site investigations [c.f. 3] and the results of these studies are of direct relevance for the safety assessment.

The novel approach for assessing the biosphere is to assign different biosphere objects which can be interconnected in an integrated landscape model. The landscape models are also created for different representations of critical time periods. This requires that the models for the objects are developed for e.g. forest, costal area, lake, and that they are able to handle site-specific data.

The interconnection of the biosphere objects is facilitated from the understanding of the surface hydrology and the locations of estimated discharge points from the repository. To be able to handle the hierarchical structure of models and inclusion of site data new modelling tools have been developed [4] and [5].

\section{APPROACH TO BIOSPHERE MODELLING}

Based on the scientific understanding of the biosphere at the site today and its development during an interglacial period, biosphere models can be constructed in which the turnover of radionuclides can be analysed. The methodology and the available tools for this are described in detail in SR-Can Interim Report [1]. 
The biosphere objects are based on ecosystem models and datasets from the sites. The two main categories of ecosystems, aquatic and terrestrial, are further subdivided into a number of ecosystem types. For instance, aquatic ecosystems include marine systems, lakes and running water and examples of terrestrial systems are agricultural land, mire and forest. For each of these, there are, in general, several possible ecosystem models that can be applied.

By introducing radionuclides at different locations in the integrated models, it is possible to follow their fate in the catchment area as they move through the connected biosphere objects, and to assess where and to what extent they may accumulate in the system. Combined with information on calculated locations of radionuclide releases from the geosphere to the surface hydrological system, this gives a view of how radionuclides become distributed through the integrated landscape model over time.

The shore-line displacement will induce changes of the internal biosphere conditions such as biosphere succession (mire and forest development) and sediment redistribution (sedimentation and resuspension/erosion). The future ecosystems will be modelled by assuming that vegetation and associated fauna will gradually migrate and follow the displacement of the shore-line. Some important processes will interact, e.g. peat development and forest succession. This can both be inferred from the existing data and be estimated in the models.

\section{INTEGRATED LANDSCAPE MODEL}

In SR-Can the biosphere is defined as a combination of specific biosphere objects having different spatial extensions and properties. Each object can be regarded as an ecosystem with an intrinsic turnover of matter. To these models the estimated locations for where the radionuclides potentially are discharged from the repository entering the biosphere from the geosphere will be added. The positions of the discharge points $(\mathrm{x}, \mathrm{y}, \mathrm{z})$ will be overlaid by the polygon describing the biosphere object.

After identification of the positions of the discharges and the associated biosphere objects, the accumulation of the discharged radionuclides downstream in the catchment will be modelled. If there are several discharge pionts entering the same catchment basin, but in different biosphere objects, these will be combined by connecting the different biosphere objects together based on site-specific maps. The maps not only describe how the biosphere objects are interconnected with each other, but also provide estimates of important parameters such as water turnover, accumulated runoff and information on how the biosphere can be utilised by humans.

\subsection{Identification of biosphere objects}

The discharge points of radionuclides from the geosphere to biosphere, obtained from the geosphere modelling were selected as an illustration of how the biosphere objects will be connected and positioned in relation to the discharge points. In this interim assessment the release were projected on to the map of the site today. In Figure 1 existing dose models from earlier assessments SR97 and SAFE [6, 7] were used with recent improvements [4, 5] as an example. From the discharge points, the major biosphere types were identified. This was straightforward for most estimated discharge points, i.e. for lakes, mires or the sea area (e.g. area 1, 8, 15 and 16). However, fringing wetlands to lakes or to the sea were more difficult (e.g. area 5 and 6). Today they are two different habitats but the border between them reflects their current stage of development. To further analyse this more details on the geometry is required. 

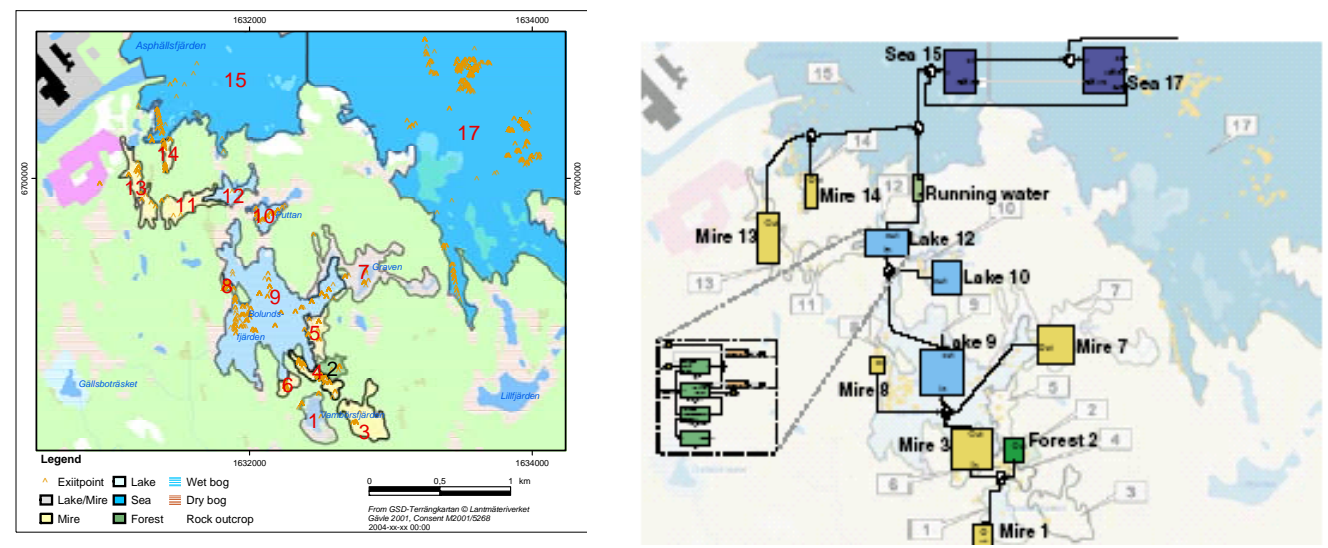

Figure 1. Map describing biosphere objects in the Forsmark area (Sweden) classified according to the identified potential discharge points of radionuclides to the biosphere (cf legend). The biosphere objects are numbered. Sea objects 16, 18 and 19 are outside the map area. Conceptual description of the landscape model where the biosphere objects are connected according to their location in the landscape. Reproduced from [1].

There are some distinctive areas of release in the sea which requires further analysis of when in time the releases are likely to occur (e.g. biosphere objects 18, 19). The advective transport times through the geosphere for these exits are more than 1000 years and have a median of almost 10000 years. This means that due to the land rise and shore-line displacement, these areas will not be coastal environments when the release occurs.

The result from this preliminary analysis shows that more than half of the exit points are located at the coastal seafloor (biosphere object 17). Approximately 5\% have also advective transport times less than 1000 years, which mean that the discharge would occur when it still is a coastal environment. Another large fraction (27\%) of estimated exit points was located in Lake Bolundsfjärden (biosphere object 9) and fringing mires (4 and 8). For the majority of the points the advective transport time is less than 1000 years. That is within the projected persistence of Lake Bolundsfjärden. Notable from this exercise is that very few exit points are located in terrestrial environments, with the exceptions of mires (biosphere object 3 , which corresponds to $0.5 \%$ of the exit points).

These findings from the preliminary data indicate that it is likely that the coast, lakes and fringing mires are the primary receivers of radionuclide discharges from the geosphere. The identified receiving biosphere objects were in the landscape model represented with connected corresponding dose models (Figure 1). The dose models and the used data are described in detail in the SR-Can interim report [8].

\section{PRELIMINARY MODELLING RESULTS}

A constant release of $1 \mathrm{~Bq} /$ year was applied to the most upstream object, identified to be the mire Varmbörsfjärden (biosphere object 1). Four hypothetical radionuclides with almost infinite half-life and with $K_{d}$ values in the range $1-1000\left(\mathrm{~m}^{3} / \mathrm{kg}\right.$ ) were simulated in the model over a period of 10000 years. In Figure 2 the total activities in the various biosphere objects are compared with the total amount of radionuclides released until that specific time.

The results show that radionuclides having lower $K_{d}$-values $\left(1 \mathrm{~m}^{3} / \mathrm{kg}\right)$ were transported through the network of biosphere objects out into the sea during the time modelled, whereas nuclides with higher $\mathrm{K}_{\mathrm{d}}$-values $\left(1000 \mathrm{~m}^{3} / \mathrm{kg}\right)$ remained almost exclusively in the first three biosphere objects nearest the discharge. The radionuclides with intermediate $\mathrm{K}_{\mathrm{d}}$-values $\left(10\right.$ and $\left.100 \mathrm{~m}^{3} / \mathrm{kg}\right)$ were found in the middle of the chain of biosphere objects, e.g. in Lake Bolundsfjärden. A considerable fraction of the released radionuclides also left the modelled system. 
Although large fractions of the radionuclides having lower $\mathrm{K}_{\mathrm{d}}$-values were transported downstream, the concentrations in water and particulate matter (i.e. peat and sediments) decreased several orders of magnitude (Figure 3). This was due to the strong dilution in the biosphere objects downstream.
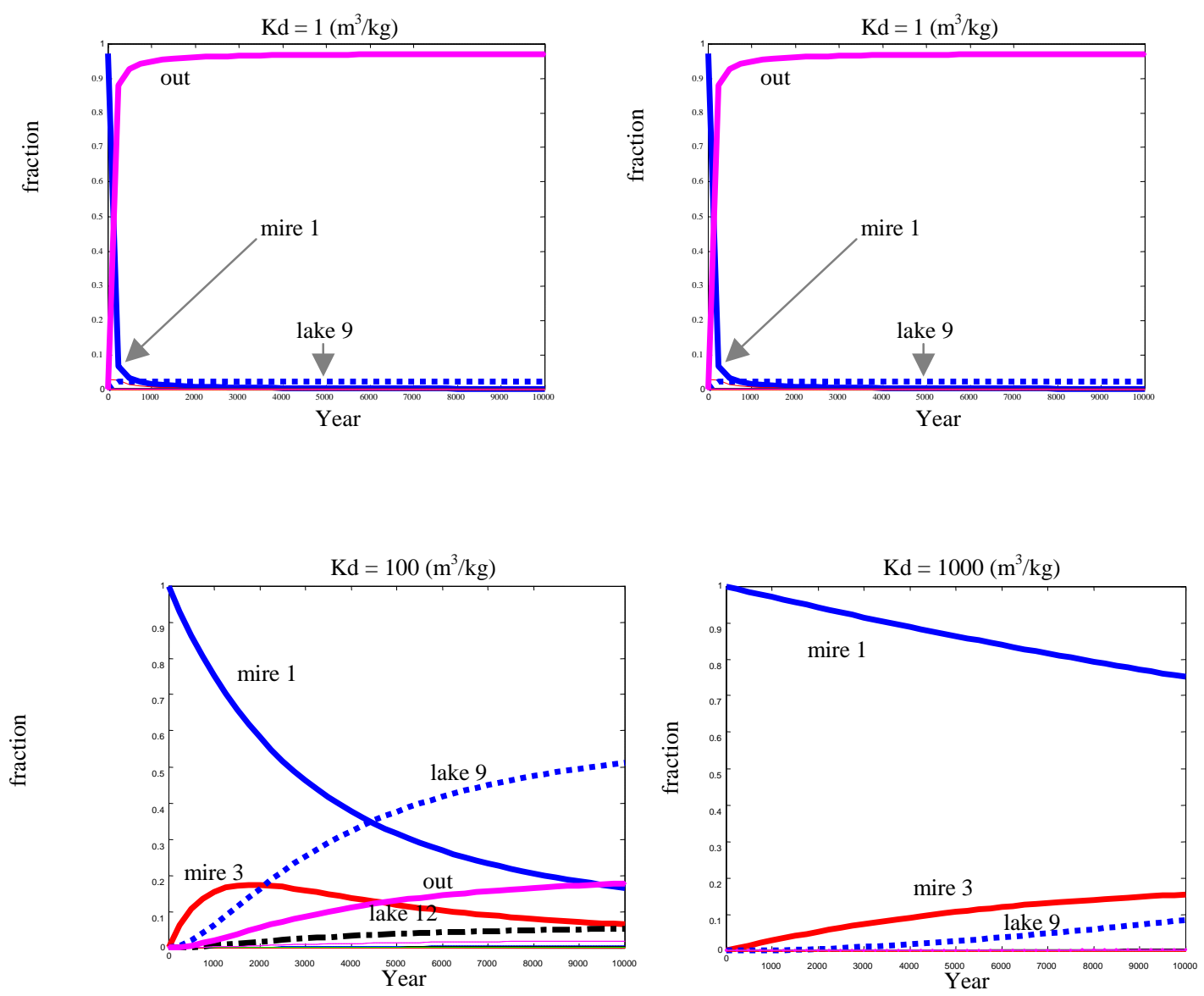

Figure 2. Locations of radionuclides from an annual unit release to Mire 1. Relative amounts of radionuclides at different times in the different ecosystems are displayed. Results for Each $\mathrm{K}_{\mathrm{d}}$ are shown in a separate panel.

\section{CONCLUDING DISCUSSION}

The results from this modelling exercise show that there are methods and tools available for landscape modelling. The model tool can both handle all discharges in individual biosphere objects and downstream radionuclide accumulation in the various biosphere objects. The model tool is also capable of handling complex site-specific information. This is an important feature to be able to link the assessment to the information available from the site. Moreover, the feedback from the dose assessment to site investigations is facilitated with such an integrated tool. 



Figure 3. Radionuclide concentrations in the soluble fraction (left) and in the particulate phase (right) of the water along the ecosystem chain for different $\mathrm{K}_{\mathrm{d}}$-values $\left(1-1000 \mathrm{~m}^{3} / \mathrm{kg}\right)$. The numbers on the horizontal axis represents the biosphere objects along the transport route (1: Mire 1, 2: Mire 3, 3: Lake 9, 4: Lake 12, 5: Sea 15, 6: Sea 17, 7: the sea outside the modelled area).

Preliminary results show that coastal ecosystems, lakes and some type of mires are the major receivers of discharges from the underground repository. They are all low points in the terrain. Thus, the potential releases in terrestrial ecosystems, e.g. forest, are few although they constitute more than half of the total area at the site.

When the fate of a constant release of radionuclides is followed, it is obvious that radionuclides with lower $\mathrm{K}_{\mathrm{d}}$-values are transported throught the network of ecosystems and are discharged to the sea and diluted in the larger recipient. In contrast, radionuclides with higher $\mathrm{K}_{\mathrm{d}}$-values are retained near the source. Independently of that the highest concentrations and the highest doses will arrive closest to the discharge points, due to the rapid dispersion and dilution downstream.

However, the overall systems behaviour needs to be explored further in a variety of site-specific contexts as the capabilities of the various object models are enhanced. That analysis will then allow generalisations.

\section{References}

[1] SKB: Interim main report of the safety assessment SR-Can, SKB-TR-04-11 (Svensk Kärnbränslehantering AB. Stockholm, Sweden) 2004.

[2] Löfgren A, Lindborg T: A Descriptive Ecosystem Model - a strategy for model development during site investigations.,SKB R-03-06 (Svensk Kärnbränslehantering AB. Stockholm, Sweden) 2003.

[3] Lindborg T, Löfgren A. ECOrad 2004.

[4] Jones J, Vahlund F, Kautsky U: Tensit -A novel probabilistic simulation tool for safety assessments- Tests and verifications using biosphere models, SKB-TR-04-07 (Svensk Kärnbränslehantering AB. Stockholm, Sweden) 2004.

[5] Jones J, Kautsky U, Vahlund CF. Ecorad2004 JOURNAL in press ECORAD.

[6] Bergström U, Nordlinder S, Aggeryd I: Models for dose assessments- Modules for various biosphere types,SKB TR 99-14 (Swedish Nuclear Fuel and Waste Mngt. Co. Stockholm, Sweden) 1999.

[7] Karlsson S, Bergström U, Meili M: Models for dose assessments. Models adapted to the SFR-area, Sweden,TR-01-04 (Swedish Nuclear Fuel and Waste Management Co. Stockholm, Sweden) 2001.

[8] SKB: Interim Data Report for the Safety Assessment SR-Can, SKB-R-04-34 (Svensk Kärnbränslehantering AB. Stockholm Sweden) 2004. 